\title{
IMPLICATURAS E A VIOLAÇÃO DAS MÁXIMAS CONVERSACIONAIS: UMA ANÁLISE DO HUMOR EM TIRINHAS
}

\author{
IMPLICATURES AND THE VIOLATION OF CONVERSATIONAL MAXIMS: HUMOR \\ ANALYSIS IN COMIC STRIPS
}

\section{Luciana Braga Carneiro Leão FAETEC / UFF / CNPq}

RESUMO: O presente trabalho tem por objetivo apresentar como o humor pode ser construído a partir de uma perspectiva pragmática. Mais particularmente, buscaremos analisar como essa construção se dá através de implicaturas e violações das máximas conversacionais, elementos esses da Pragmática Conversacional de Grice $(1957$; 1975). Para tal, utilizaremos como corpus de análise quatro tirinhas de humor de diferentes autorias. São elas duas tirinhas do Garfield - personagem criada pelo americano Jon Davies, no final da década de 70 e publicada até os dias atuais -, uma de humor memede autoria desconhecida por ser um estilo de tirinha que tem como característica o fato de que pode ser produzida por qualquer internauta e divulgada na rede - e uma da Mafalda - personagem criada pelo argentino Quino e publicada originalmente entre os anos de 1964 e 1973.

PALAVRAS-CHAVE: Implicaturas; Violação das Máximas Conversacionais; Humor; Tirinhas.

ABSTRACT: This paper aims to present how humor can be constructed from a pragmatic perspective. More specifically, we intend to analyze how this construction is developed through implicatures and violations of conversational maxims, elements of Grice's Conversational Pragmatics (1957; 1975). For that purpose, its analysis corpus will be composed by four comic strips of different authorship. They are two Garfield strips - a character created by American Jon Davies in the late 70s and published to present day - a humoristic meme - a comic style of unknown authorship since it is characterized by the fact that it can be produced by any internet user and published on the web - and one from Mafalda - a character created by Argentine Quino and originally published between 1964 and 1973.

KEYWORDS: Implicatures; Violation of Conversational Maxims; Humor; Comic strips.

\section{INTRODUÇÃO}

As tirinhas são um gênero textual amplamente conhecido e divulgado nos mais diversos suportes. Encontramo-las em jornais, revistas, revistas em quadrinho (HQs), internet, dentre outros. Via de regra produzidas com o objetivo de construir humor e levar o leitor ao riso - e, por vezes, com o intuito de crítica e reflexão social embutido nesse humor -, as tirinhas podem ser analisadas pela perspectiva da Pragmática Conversacional (GRICE, 1957; 1975). Isso porque, no gênero tirinha, o uso linguístico dá-se em meio a um contexto situacional e através da negociação de sentido entre interlocutores - mesmo que fictícios -, característica essa da conversação. 
Assim sendo, seus textos fazem uso de conteúdos implícitos, que podem ser alcançados tanto pelos interlocutores fictícios - as personagens - quanto os reais - os leitores através do princípio cooperativo e suas respectivas máximas conversacionais (GRICE, 1957; 1975). E, principalmente, muitas vezes, o humor será produzido justamente pela quebra das expectativas que esse princípio e suas máximas trazem - quebra essa conhecida como violação das máximas conversacionais.

As violações de máximas conversacionais são intencionais e, acima de tudo, são alcançadas, aceitas e compreendidas pelos interlocutores. Isso significa dizer que, tanto os implícitos quanto as violações das máximas não são, em nenhum momento, uma tentativa do locutor de enganar ou omitir informações, mas sim recursos conversacionais para uma compreensão rápida e que causa efeito no interlocutor. Tais resultados são justamente o motivo desses recursos serem tão frequentes no humor e, em especial, nas tirinhas, uma vez que esse gênero possui por intuito provocar o riso nos leitores, através da tentativa de transmitir e causar o efeito necessário num espaço curto.

\section{FUNDAMENTAÇÃO TEÓRICA}

Para que possamos compreender as tirinhas de humor que serão apresentadas no corpus de análise, faz-se necessário, primeiramente, que abordemos alguns pressupostos teóricos que permeiam as áreas de texto, contexto, pragmática e humor.

\subsection{TEXTO E CONTEXTO}

Até a primeira metade do século XX, o texto era considerado apenas uma sequência ou combinação de frases que faziam sentido por si sós. No entanto, com o surgimento das primeiras teorias pragmáticas na segunda metade daquele século, o texto começa a ser visto como o ambiente de interação entre sujeitos. Assim, para que seja possível atribuir sentido a todos os elementos textuais, os pragmaticistas apontavam a necessidade de verificar a situação em que a comunicação se inseria (KOCH e ELIAS, 2007).

Dessa forma, verifica-se a importância do contexto sociocognitivo, isto é, dos conhecimentos enciclopédicos, lógicos, de experiência, dentre outros, dos sujeitos da interação somados aos dados situacionais que circundam a interlocução. O conceito de contexto, segundo Armengaud (2006, p.13), diz respeito à “(...) situação concreta em que os atos de fala são emitidos, ou proferidos, o lugar, o tempo, a identidade dos falantes etc., tudo o que é preciso saber para entender e avaliar o que é dito...".

Verifica-se, portanto, que o contexto é de extrema importância para a produção de sentido de um texto, uma vez que essa significação não é prévia, mas sim formada durante a interação dos sujeitos do texto. Isso porque, independente do texto ser oral ou escrito, além das palavras que o compõem, há uma multiplicidade de recursos que são utilizados e que só podem ser compreendidos pelo contexto situacional e sociocognitivo.

Para explicar o que significa contexto, Koch (2006, p.59) utiliza a metáfora do iceberg que ilustra de maneira simples e clara o seu conceito, juntamente com o de conteúdo explícito e implícito : 
[...] a metáfora do iceberg - que tem uma pequena superfície à flor da água (o explícito) e uma imensa superfície subjacente, que fundamenta a interpretação (o implícito), podemos chamar de contexto o iceberg como um todo, ou seja, tudo aquilo que, de alguma forma, contribui para ou determina a construção do sentido.

Observa-se, assim, que, para a construção do sentido no texto, o locutor pressupõe a participação do interlocutor. Não é necessário que haja coincidência em relação à compreensão do texto e do leitor, no entanto, é fundamental que eles possam interagir de maneira dinâmica. E, para ocorrer tal interação, é necessário que o contexto seja compreendido pelo leitor. Essa interação dinâmica, muitas vezes, dá-se através das questões pragmáticas que envolvem o texto.

\subsection{PRAGMÁTICA}

A Pragmática estuda a língua pelo ponto de vista dos usuários, observando tanto as escolhas feitas pelo autor, quanto o que ocorre quando se usa a língua em intenção social, além dos efeitos do uso sobre outros participantes em um ato de comunicação. Assim sendo, essa área da Linguística se ocupa de estudar o significado não das palavras isoladas de seu contexto, mas sim das palavras utilizadas em atos de comunicação. Na perspectiva pragmática, atentamos aos princípios e à prática do desempenho conversacional, observando-se todos os aspectos do uso e entendimento da língua.

Austin (1962) apresenta e Searle (1969) desenvolve a Teoria dos Atos de Fala para dar conta das ações praticadas através do enunciado. De acordo com Austin (1962), a comunicação não é composta apenas de palavras e estruturas gramaticais, mas também de ações, isto é, dizer é agir. Uma mensagem verbal, frequentemente, não é apenas uma transmissão exata de informação. Quando um locutor pronuncia "Está calor aqui”, por exemplo, pode estar fazendo mais do que apenas constatar a temperatura. Ele pode estar pedindo que seu interlocutor abra a janela, ligue o ventilador ou o aparelho de ar condicionado, pode estar convidando-o para se dirigirem a outro local, pode estar justificando suas roupas, ou diversas outras interpretações. Assim sendo, com a linguagem, podemos fazer muito mais do que apenas dizer algo; ela nos permite fazer algo, agir sobre o mundo.

O autor distingue, então, dois tipos de elocuções: as constativas e as performativas. As primeiras são aquelas utilizadas para descrever o estado de algo ou relatar fatos e eventos, enquanto as outras são aquelas que também são uma forma de ação. Austin (1962) define ainda três atos que são realizados simultaneamente durante a enunciação. $\mathrm{O}$ ato locucionário é a realização do ato de dizer algo. Ele tem sentido e referente. Já o ato ilocucionário é a realização de um ato ao dizermos algo. Esse carrega uma força quando dito. E, finalmente, o ato perlocucionário é o efeito alcançado pelo dizer algo. Segundo o autor, a unidade básica da comunicação é o ato ilocucionário - no qual se encontram as elocuções constativas e performativas - pois seria o único fenômeno real na situação de fala que nos empenhamos em elucidar, i.e., é nesse ato que o falante expressa suas intenções.

Dando continuidade aos estudos de Austin (1962), Searle (1969) acrescenta uma 
taxonomia de atos ilocucionários. O autor afirma que podemos imaginar quais sejam algumas das intenções do locutor ao analisarmos o contexto em que a interação ocorre e os objetivos que intenciona alcançar. Assim sendo, o número de usos da linguagem seria finito. Eles seriam a descrição, a persuasão, a assunção de compromissos, a expressão de sentimentos e atitudes e a mudança do estado de algo. Searle (1969) expande a Teoria dos Atos de Fala também ao incluir nas classes de atos de fala os atos de fala indiretos. Os atos de fala indiretos são aqueles executados indiretamente através da realização de outro ato de fala ou por locuções com performativos implícitos . O significado dessa categoria de atos é alcançado através de ferramentas comunicativas como o Princípio Cooperativo, a informação partilhada e a capacidade do ouvinte de fazer inferências.

Dessa forma, ao analisarmos um texto sob a ótica pragmática, não podemos nos prender à visão de texto como conjunto de palavras e frases isoladas e de significado explicitado através dessas. Um dos postulados primordiais da Pragmática é o de que em um ato ilocucionário há dados explícitos e implícitos sendo transmitidos. Para uma compreensão total do texto é necessário identificar e compreender ambos, uma vez que são partes que se complementam da enunciação.

\subsection{EXPLÍ́CITO X IMPLÍCITO}

Numa situação de comunicação, percebe-se uma necessidade constante dos enunciadores complementarem o conteúdo da informação a partir de elementos implícitos. Assim sendo, o ato de linguagem possuiria uma dupla dimensão ou valor: explícito e implícito (CHARAUDEAU, 2009).

Na maioria dos textos, há informações que são transmitidas de maneira explícita, enquanto outras estão implícitas. Nessas situações, o que um falante quer dizer vai além daquilo que ele diz de fato. Essa informação que o falante quer dizer para além daquilo que diz é o que ele sugere, indica, insinua, etc. Essas sugestões, indicações, insinuações são identificadas pelo ouvinte/leitor, não através da descodificação do significado linguístico, mas através de inferências (GRICE, 1957).

Assim, para entender o que um texto está querendo dizer, é necessário entender o que está explícito e captar todas as informações que estão implícitas, ou seja, como se diz popularmente, é indispensável ler o que está escrito nas entrelinhas. De acordo com Charaudeau (2009, p.24),

A finalidade do ato de linguagem (tanto para o sujeito enunciador quanto para o sujeito interpretante) não deve ser buscada apenas em sua configuração verbal, mas, no jogo que um dado sujeito vai estabelecer entre esta e seu sentido implícito. Tal jogo depende da relação dos protagonistas entre si e da relação dos mesmos com as circunstâncias de discurso que os reúnem.

Observa-se, assim, que esse jogo de relações é variável, pois, quando há um conteúdo implícito, há diversas hipóteses de interpretação, dependendo dos diferentes pontos de vista dos falantes envolvidos na comunicação. Portanto, em todo ato de comunicação, deve-se considerar as circunstâncias em que se efetivou a produção, bem como a intencionalidade do locutor.

Work. Pap. Linguíst., 13(1): 65-79, Florianópolis, jan./mar, 2013 
O conteúdo que está explícito não é de difícil compreensão, uma vez que este está expresso de maneira clara. Já o que está transmitido de maneira implícita - o não dito requer uma atenção maior do leitor, pois esse conteúdo, por sua vez, não está apresentado com a mesma clareza. Assim sendo, uma mesma elocução pode sugerir, indicar, insinuar, etc., coisas diferentes em contextos diferentes. Em geral, é a partir da identificação do que é dito que se infere o não dito.

Para Grice (1975), a significação total de uma elocução envolve tanto o que é dito como as eventuais implicaturas, ou seja, as informações que são dadas pelo locutor de maneira implícita. Assim, e tendo em conta o papel das intenções na significação e na comunicação, conclui-se que as implicaturas são intencionais, assim como "o que é dito". É necessário, portanto, que se compreenda tanto o que o enunciador diz de maneira explícita quanto o que ele quer dizer de maneira implícita.

\subsection{PRAGMÁTICA CONVERSACIONAL}

A análise dos conteúdos implícitos a serem transmitidos no ato ilocucionário que não poderão ser depreendidos a partir de uma análise meramente decodificadora é o foco de estudo de uma subárea da Linguística denominada Pragmática Conversacional. Esses estudos são inaugurados pelo pragmaticista Paul Grice $(1957$; 1975) ao tratar da distinção entre significado do falante e significado da sentença, descrevendo as relações que supõe existir entre o que é dito - as palavras utilizadas e suas implicaturas convencionais - e o não-dito - o que é implicado de forma não-convencional numa troca comunicativa. $\mathrm{O}$ que é dito no proferimento de uma sentença está intimamente relacionado ao significado convencional das palavras utilizadas. Ao implicar conversacionalmente algo, no entanto, o falante demonstra sua intenção de comunicar uma ideia diferente daquela que as palavras empregadas expressam literalmente.

\subsection{PRINCÍPIO COOPERATIVO}

Para Grice (1975), numa situação de diálogo, os interlocutores assumem de maneira implícita um contrato conversacional; um conjunto de normas que regem a conversação. A regra geral desse contrato, o autor denomina Princípio Cooperativo e suas respectivas subrregras seriam as máximas de qualidade, quantidade, relação e modo. O autor sustenta que o sucesso da comunicação é garantido porque os interlocutores partilham das mesmas estratégias de preservação e violação dessas máximas.

O Princípio Cooperativo indica que o locutor "dê a sua contribuição conversacional tal como requerida, na altura em que ocorre, pelo propósito ou direção aceitos da troca verbal na qual você está envolvido" (GRICE, 1957, apud YULE , 1996, p. 37). Esse princípio divide-se em quatro subprincípios, apresentados como Máximas Conversacionais, são elas: Máxima da Quantidade, Máxima da Qualidade, Máxima da Relação e Máxima do Modo, conforme seguem abaixo.

Máxima da quantidade

- Faça com que a sua contribuição seja tão informativa quanto o necessário.

- Não faça a sua contribuição mais informativa que o necessário. 
Máxima da qualidade

- Tente fazer com que a sua contribuição seja verdadeira.

- Não diga aquilo que acredita ser falso.

○ Não diga aquilo para o que não possui evidência suficiente.

Máxima da relação

- Seja relevante.

Máxima do modo

- Seja claro.

○ Evite obscuridade de expressão.

$\circ$ Evite a ambiguidade.

- Seja breve.

- Seja organizado.

É importante observar que essas máximas já são pressupostas pelos interlocutores e que não necessitam ser explicitadas e acordadas previamente por já fazerem parte de um contrato comunicativo, ou seja, elas são presumidas em interações normais. Os interlocutores presumem que as pessoas, normalmente, fornecerão uma quantidade apropriada de informações, que falarão a verdade, que serão relevantes e que procurarão ser o mais claras possível.

\subsection{IMPLICATURAS}

Em sua Teoria das Implicaturas, Grice (1975) afirma que o elemento central da comunicação é o reconhecimento, por parte do ouvinte, da intenção que o falante possui de induzir com seu proferimento. Esse é o ponto de partida para que se faça sentido do que é dito. Os participantes da conversa, a princípio, cooperam um com o outro. Esse senso de cooperação é o que leva o interlocutor a crer que o locutor não está tentando enganá-lo em suas proposições. Quando o que é dito não é suficiente para que se extraia sentido da fala do locutor, o interlocutor acredita que há algo mais implicado e tenta chegar a essa informação por conta própria para compreender o que o locutor está querendo transmitir. Esse algo a mais a ser entendido pelo interlocutor são as implicaturas.

Existem dois tipos de implicaturas. São elas as Implicaturas Convencionais e as Implicaturas Conversacionais. As implicaturas convencionais são aquelas que estão presas ao significado convencional das palavras, ou seja, ao significado literal das palavras. Para este conceito cabe o exemplo a seguir:

[1] José é trabalhador, contudo é pobre.

No exemplo [1], implica-se convencionalmente que José sendo trabalhador não deveria ser pobre, mas o é. O uso literal dos termos nos dá ideia exata do que está sendo dito através da conjunção contudo. Podemos perceber, portanto, que as implicaturas convencionais não dependem de contextos especiais para interpretação, e, com isso, não precisam ocorrer necessariamente na conversação. Elas são associadas a palavras 
específicas e resultam em significados adicionais vindos das informações que essas palavras transmitem. Podemos verificar, portanto, que as implicaturas convencionais são aquelas que são depreendidas através da decodificação.

No uso das implicaturas conversacionais, há uma ruptura entre os enunciados que necessita de um preenchimento por parte dos envolvidos no ato comunicativo para haver sentido, como veremos no exemplo a seguir.

[2] Alice: Espero que você tenha trazido o pão e o queijo.

Bruno: Eu trouxe o pão.

Nessa conversa, Alice parte do princípio que Bruno está cooperando com o diálogo e não desconhece a máxima da quantidade. Ainda assim, ele não mencionou o queijo. Se ele tivesse trazido o queijo, ele o mencionaria também, não violando, assim, a máxima da quantidade. Resulta daí que Bruno intenciona que Alice infira que o que não foi mencionado, não foi trazido. Dessa forma, Bruno transmitiu mais do que o dito através de uma implicatura conversacional.

As implicatura conversacionais, diferentemente das convencionais, não dependem da significação usual, sendo determinada por certos princípios básicos do ato comunicativo. É importante destacar, portanto, que é o locutor que transmite significação através das implicaturas e que a função do interlocutor é a de reconhecê-las através de inferências. As inferências selecionadas serão aquelas que preservem o pressuposto da cooperação.

\subsection{VIOLAÇÃO DAS MÁXIMAS CONVERSACIONAIS}

Verificamos que, no processo de interação e cooperação, muitas vezes é preciso violar algumas máximas conversacionais para que se possa produzir um determinado efeito de sentido no interlocutor. Analisemos o seguinte cenário.

[3] Em uma entrevista de emprego, o entrevistador chega à conclusão de que o candidato não lhe serve. $\mathrm{O}$ entrevistador diz então ao candidato:

- Acho que você seria mais feliz em uma empresa maior... ou menor.

No exemplo [3], o entrevistador não segue a máxima da qualidade, já que ele não está dizendo o que realmente pensa, ou mesmo a máxima de modo, já que está sendo ambíguo e contraditório. No entanto, o entrevistador viola essas máximas não para enganar ou mentir para o candidato, mas apenas para dar seu parecer negativo de maneira mais branda. Ele implica sua resposta - o não-dito - através de sua suposta opinião - o dito. O princípio cooperativo não é violado, apenas as máximas, uma vez que o candidato, por reconhecer a função do entrevistador de selecionar e descartar candidatos, infere a implicatura de que fora descartado.

Quando o locutor parece não seguir as máximas conversacionais, mas ainda assim espera que o interlocutor infira o sentido implícito, dizemos que ele está cometendo uma Violação das Máximas Conversacionais. Ao violar uma máxima, o locutor presume que o interlocutor compreende que suas palavras não devem ser consideradas literalmente e que ele é capaz de inferir a intenção implícita. 
O locutor viola a máxima da quantidade quando parece dar pouca informação ou mais do que o necessário.

[4] Alfredo: Como estou?

Beatriz: Seus sapatos estão bonitos.

Um falante pode violar a máxima da qualidade de diversas formas. Uma delas é, como vimos no exemplo [3], dizendo algo que obviamente não é o que realmente pensa. Outra forma é através de exageros como os encontrados em hipérboles e metáforas, de eufemismos, ironias e de brincadeiras amistosas (banters).

[5] Eu poderia comer um boi!

[6] Alberto: Como foi a viagem?

Bruce: A suíte em que fiquei era um forno!

[7] Ela bateu as botas

[8] Se você soubesse o quanto eu gosto de acordar com berros no meu quarto às 4 da madrugada ...

[9] Seu safado e sem-vergonha! Você não vai me dar um beijinho?

Ao violar a máxima da relação, o locutor espera que seu interlocutor seja capaz de imaginar uma sentença não-proferida e que estabeleça a conexão entre as ditas anteriormente.

[10] Augusto: Você aceita um sorvete?

Bianca: Estou ficando gorda.

Numa violação da máxima do modo, o enunciador aparenta ser obscuro, o que normalmente ocorre para excluir um terceiro da conversa. Ainda assim, o locutor parte do princípio de que seu interlocutor intencionado será capaz de inferir a implicatura, enquanto o terceiro que eles desejam excluir da conversa não possuirá a mesma capacidade. lado.

[11] Um homem conversa com sua esposa, enquanto a filha pequena brinca ao

-Estou pensando em sair para arranjar uma coisinha gelada e gostosa pra alguém.

Veremos, mais à frente, exemplos das quatro formas de violação das máximas conversacionais analisadas dentro de seus contextos situacionais. Por esse motivo, optamos por apenas apresentar exemplos de violação na presente secção, com intuito ilustrativo. Antes de seguirmos com a apresentação e análise do corpus, no entanto, fazse necessário que discutamos os motivos que levam um locutor a violar as máximas conversacionais. 


\subsection{Humor}

O humor pode se dar através das mais diversas formas, sejam elas críticas, escárnio, quebra de expectativa, ou outras. Independente da forma em que se dê, para Travaglia (1990), o humor é uma forma de revelar e de flagrar possibilidades de visão do mundo e das realidades culturais que nos cercam. Assim sendo, o humor é uma "manifestação comunicativa por excelência" (ZIRALDO, 1970 apud TRAVAGLIA, 1990). Como em qualquer outra situação comunicativa, temos, no humor, um locutor que intenciona transmitir algo - no caso, uma informação que causa o riso - a um interlocutor. Portanto, sendo analisado por uma perspectiva de conversação, o humor pode ser explicado por princípios teóricos, como confirma o autor (TRAVAGLIA, 1990, p.63) quando aponta que "todo o humor resultante do desrespeito às regras conversacionais pode ser explicado, utilizando os princípios teóricos da análise da conversação".

Seguindo os mesmos preceitos, Raskin (1985) indica que o humor é uma forma de comunicação social. Assim, o autor adapta o Princípio Cooperativo de Grice (1975), mostrando que uma comunicação bona-fide é governada por esse princípio, enquanto uma comunicação não-bona-fide tem o propósito de criar uma expectativa diferente da verdade, um efeito especial com objetivo de fazer o ouvinte rir ou inferir alguma situação. No primeiro caso, há toda uma preocupação em dizer a verdade e ser coerente, é um modo sério que prevê a obediência às máximas conversacionais do Princípio Cooperativo. Já no modo não-bona-fide, os falantes e ouvintes não se preocupam com a verdade, há a quebra das máximas de Grice (1975) e com isso, o aparecimento do riso. Para a construção do humor, o autor afirma que é preciso passar do modo bona-fide para o modo não-bona-fide. Ao adotar o modo não-bona-fide o falante e o ouvinte estabelecem outro tipo de interação; eles estão cientes dessa nova abordagem e estão em comum acordo de que não encontrarão mais a verdade e a coerência, mas sim o lúdico e o inesperado.

Com base nos pressupostos teóricos apresentados acima, podemos concluir que a análise das tirinhas apresentadas no presente trabalho deve partir do aspecto conversacional da produção do humor. Para tal, a teoria das implicaturas e o princípio cooperativo - especialmente na questão da violação das máximas - serão o ponto de partida para esse estudo.

\section{ANÁLISE DE CORPUS}

Apresentamos, a seguir, quatro tirinhas de humor; sendo duas tirinhas do Garfield, uma de humor meme e uma da Mafalda. Em cada uma dessas tirinhas, é possível identificar pelo menos uma violação de máximas conversacionais. As violações, como discutimos anteriormente, são intencionais. O locutor espera que seu interlocutor seja capaz de inferir o não-mencionado. Assim sendo, o princípio cooperativo se mantém, apesar das violações. No caso do corpus desse trabalho, a intenção por trás dessas violações é a produção de humor. 


\subsection{VIOLAÇÃO DA QUANTIDADE}
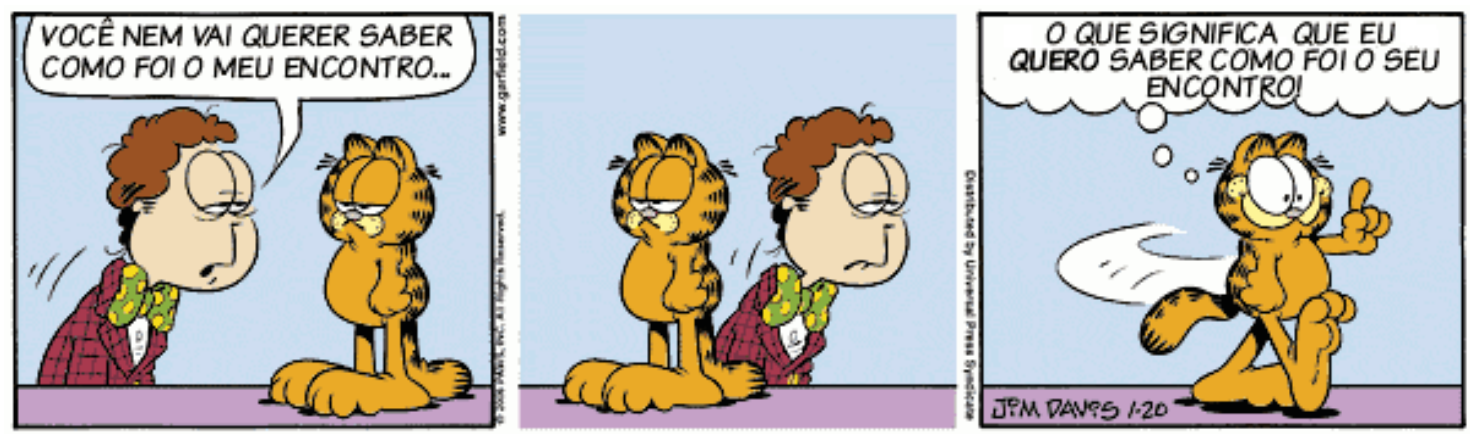

Figura 1 Tirinha do Garfield

Fonte: <http://tirinhasdogarfield.blogspot.com.br/>

Nesse exemplo, Jon, o dono de Garfield, viola em sua fala a máxima da quantidade. Mais especificamente, viola o ponto da máxima que diz "Faça com que a sua contribuição seja tão informativa quanto o necessário", pois não fornece informações o suficiente para que se compreenda o porquê de estar chateado. No entanto, Jon sabe que não está dando todas as informações de maneira explícita. Implicitamente, encontra-se sua indicação de que o encontro não ocorreu da maneira que desejava, provavelmente devido a algum acontecimento desagradável durante o mesmo, ou até a uma série de acontecimentos desagradáveis. Após alguns segundos de reflexão, Garfield chega à conclusão de que esses acontecimentos, que para Jon foram desagradáveis, para ele seriam interessantes, e até mesmo uma forma de diversão. Por conta disso, vai atrás de seu dono para obter maiores detalhes.

Muitas vezes, utilizamos construções como essa de Jon ou similares, como por exemplo, "Você não sabe o que me aconteceu" e "Nem te conto o que aconteceu" - com o intuito de introduzir uma narrativa. A implicatura por trás dessas sentenças é a de que existe algo que o locutor sabe e gostaria muito de narrar ao seu interlocutor. Utilizamos essas construções como forma de iniciar nossa narrativa. Essas introduções podem ser, até mesmo, maneiras utilizadas pelo locutor para checar se seu interlocutor tem interesse e disponibilidade de tempo para ouvir a estória completa. $\mathrm{O}$ interlocutor compreende que há muito mais a ser contado e que o locutor tem interesse em lhe contar. Consequentemente, fornecerá uma resposta com a qual pede - e, assim, permite - que o primeiro forneça uma narrativa detalhada.

Expressões como as exemplificadas acima já estão no conhecimento popular como possuidoras de significado próprio, sendo conhecidas, portanto, como expressões cristalizadas. De acordo com Xatara (1998, p. 2), expressões desse tipo são "uma lexia complexa, indecomponível, conotativa e cristalizada em um idioma pela tradição cultural". A indecomponibilidade de uma expressão cristalizada diz respeito ao fato de que praticamente não há possibilidade de substituição por associações paradigmáticas. No que diz respeito à conotação, Xatara (1998) intenciona que sua interpretação semântica não pode ser feita com base nos significados de suas unidades individualmente. E quanto à cristalização, o que o autor pretende apontar é que o significado da expressão já está consagrado na comunidade em que é utilizada como 'estável'.

Podemos afirmar, portanto, que a cristalização ocorre a partir do momento em que os 
significados das palavras não podem ser entendidos 'ao pé da letra', pois o significado não é dedutível dos valores das palavras que compõem a expressão. Assim sendo, entende-se que quando uma expressão passa a ter um significado diferente de seus constituintes, a forma linguística foi cristalizada.

\subsection{VIOLAÇÃO DA QUALIDADE}
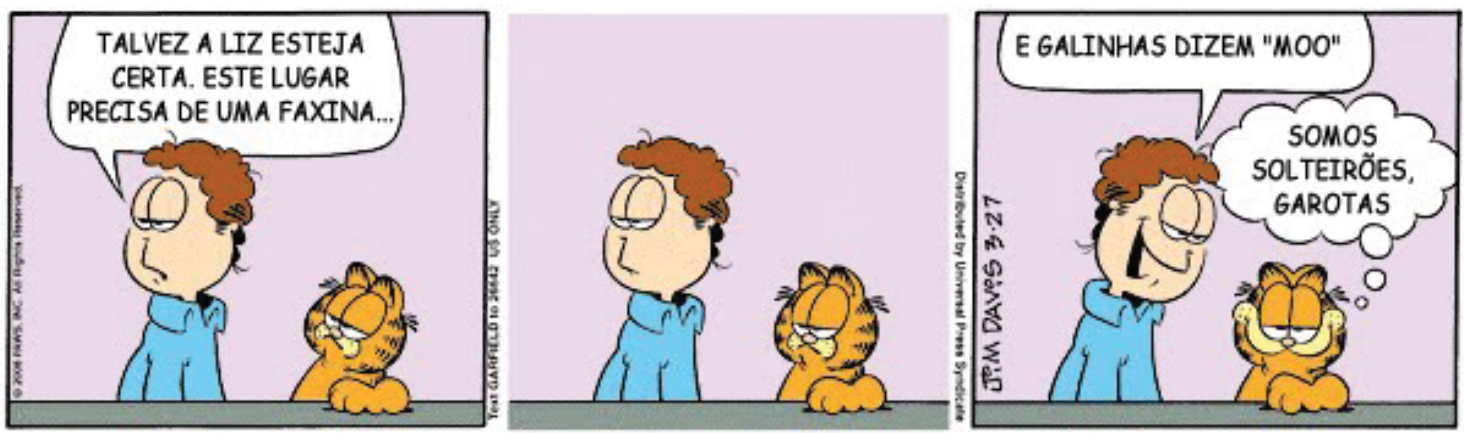

Figura 2 Tirinha do Garfield

Fonte: <http://tirinhasdogarfield.blogspot.com.br/>

Na tirinha acima, a segunda fala de Jon viola a máxima conversacional em que devemos tentar fazer com que a nossa contribuição seja verdadeira, onde uma das formas de se alcançar é não dizendo aquilo que acreditamos ser falso. Jon afirma "E as galinhas dizem moo", indicando convencionalmente que as galinhas mugem. No entanto, o rapaz sabe que esse dado não é verdadeiro e as galinhas, na verdade, cacarejam. Ainda assim, a intenção de Jon não é a de enganar alguém, tentando convencer Garfield de uma mentira. A insinuação de uma negação está implícita à sua sentença, ou seja, a implicatura de que, tal qual as galinhas não cacarejam, Liz não tem razão e o seu apartamento não precisa de uma faxina.

É importante observar ainda que há, a princípio, uma inferência convencional na afirmação "Este lugar precisa de uma faxina". No entanto, após refletir sobre a mesma, Jon realiza uma transgressão estratégica intencional e, então, recategoriza o pressuposto convencional inicial ao dizer "E as galinhas dizem "moo". Desse modo, a fala inicial é verdadeira, e a violação só acontece após a recategorização.

Percebe-se claramente nesse exemplo o papel de caráter extremamente relevante do contexto na compreensão das implicaturas. Apesar da sentença "E as galinhas dizem moo" convencionalmente ser afirmativa, outros elementos contextuais, como a expressão facial de Jon, indicam que aquilo obviamente não é algo que ele acredite ser verdadeiro.

Podemos observar, ainda, que a última fala de Jon, explicitamente, não possui nenhuma relação com o que falava anteriormente. No entanto, há uma relação implícita de que, tal qual as galinhas não mugem - e sim cacarejam -, Jon acredita que sua casa não necessita de uma faxina, ao contrário do que afirmara Liz. Do mesmo modo, a fala de Garfield, aparenta não possuir nenhuma relação como tudo que havia sido dito anteriormente. Mas, por trás do significado convencional, encontra-se a implicatura de que homens solteiros não se importam tanto com a limpeza de sua moradia quanto as mulheres. Essas implicaturas se dão através da violação da máxima da relação, conforme veremos a seguir. 


\subsection{VIOLAÇÃO DA RELAÇÃO}

Figura 3: Tirinha meme

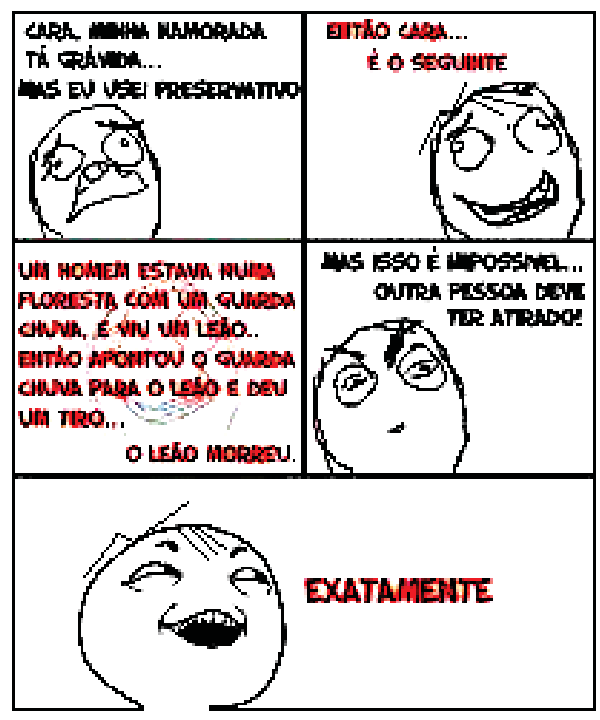

Fonte: <http://tirinhas-meme.tumblr.com/>

A máxima da relação prega que devemos ser relevantes em nossas proposições, o que significa dizer que nossa fala deve ser coerente, isto é,. ter relação, com o que foi dito anteriormente. A tirinha apresentada inicia com um rapaz contando a seu amigo que sua namorada está grávida apesar de eles terem usado preservativo em suas relações sexuais. O amigo, no entanto, prossegue o diálogo com uma narrativa em que descreve um homem em meio à floresta, que, ao se perceber em perigo com a aproximação de um leão, aponta seu guarda-chuva para o animal e esse, em sequência falece com um tiro. Essa narrativa, a princípio, foge por completo do tema "gravidez e uso de preservativos", que o primeiro rapaz havia trazido para a interação. Esse resolve permanecer no tema abordado pelo amigo - "guarda-chuvas como armas letais que fazem uso de munição" - retrucando que outra pessoa provavelmente teria atirado de uma arma de verdade. O rapaz mantém a relevância ao ater-se ao novo tópico da conversa.

Seu amigo, por seguinte, afirma "exatamente". Nessa sentença encontramos duas implicaturas. A implicatura convencional é a de que o rapaz está correto e realmente havia sido outra pessoa que atirou no leão, levando-o a óbito. No entanto, o humor se dá na implicatura conversacional que também se encontra na última fala do amigo. Ao implicar convencionalmente que o rapaz está correto ao dizer que outra pessoa atirou no leão, o amigo implica também que, da mesma forma, outra pessoa havia engravidado a namorada do rapaz.

Indiretamente, a narrativa do amigo relaciona-se à fala anterior do rapaz. Ao narrar a estória do homem com o guarda-chuva e o leão, o amigo não estava abordando um assunto que não possuía relação com o problema do rapaz. Contrariamente, as duas falas se relacionam, pois narram situações em que alguém acreditava ser responsável por algo que não teria como ter feito, quando, na realidade, outras pessoas havia cometido essas ações. A aparente violação de relação é dissolvida ao imaginarmos uma fala não-dita, porém implicada, que liga os dois ditos. 


\subsection{VIOLAÇÃO DO MODO}
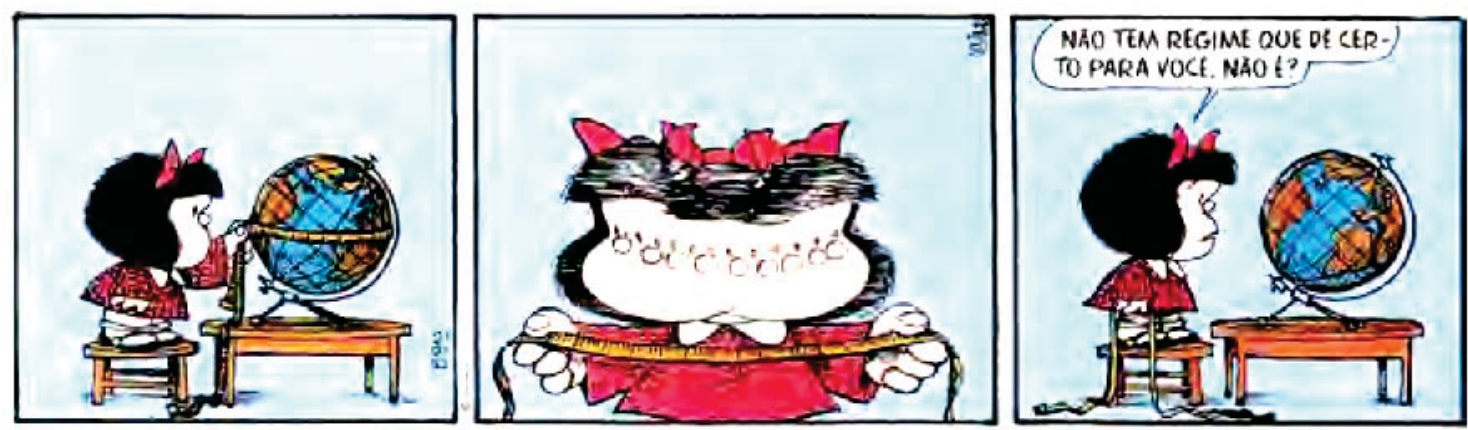

Figura 4:Tirinha Mafalda

Fonte: QUINO, 2003).

A fala de Mafalda parece faltar com a máxima do modo, pois não segue a proposição "seja claro", principalmente no que diz respeito a evitar ambiguidades. O uso da fita métrica por Mafalda para medir a circunferência do globo terrestre, seguido do termo regime, remete ao sentido de dieta, redução alimentar com fins de emagrecimento. No entanto, a relação entre regime e o planeta Terra, por outro lado, se refere não à forma física do planeta, mas sim às formas de governo existentes ao redor do mundo.

O que gera esse caráter dúbio na tirinha é a ambiguidade polissêmica presente no termo regime. Esse vocábulo assume dois significados distintos: dieta e formas de governo. A escolha entre as duas implicaturas não pode ser feita de maneira convencional pelo leitor uma vez que linguisticamente ambas são possíveis, e paralinguisticamente ambas estão representadas nas imagens, ou seja, nas relações fita métrica e regime, e mundo e regime. É essa ambiguidade que traz humor à tira, justificando assim a violação da máxima do modo.

Devemos considerar ainda o contexto histórico das tirinhas de Mafalda em geral. Enquanto criança, Mafalda é muito nova para estar preocupada com a situação governamental e mundial. Contudo, como se sabe, as tirinhas de Mafalda foram escritas e publicadas por Quino entre 1964 e 1973 na Argentina, que vivia, na época, sob regime ditatorial. Por conta disso, as tirinhas de Mafalda apresentam um viés político marcante: através das personagens infantis, seu autor externava sua visão crítica da realidade levando seus leitores a refletirem sobre ela.

Percebe-se, assim, um caráter de uso abundante de implicaturas - e implícitos em geral, pois, ao levar o leitor a interpretar e alcançar o não-dito, Quino pode transmitir sua opinião. O mesmo seria impossível de ser colocado abertamente durante o regime militar sem sofrer severas punições. Através dos implícitos, Quino podia transmitir sua posição política e induzir o leitor a uma postura crítica, sem que fosse percebido pela censura, o que gera certa forma de humor por si só. 


\section{CONSIDERAÇÕES FINAIS}

Esse trabalho teve como objetivo apresentar como o humor pode ser construído através do discurso, principalmente sob a forma de implicaturas e violações das máximas conversacionais. Para muitos linguistas, a noção de implicaturas é um dos pontos centrais da Pragmática. Isso porque elas são, sem sombra de dúvida, um dos maiores exemplos de que comunicamos muito mais do que aquilo que dizemos em si. Juntamente a tópicos como os pressupostos e os atos de fala, as implicaturas nos levam ao cerne dos estudos pragmáticos, que revolucionaram a forma de analisarmos os textos e as informações contidas neles.

Assim sendo, analisar textos complexos - como os de humor - sob a perspectiva pragmática faz-se extremamente necessário para que possamos alcançar o real objetivo almejado por seus autores ao produzi-los. Dessa forma, o humor, pelo seu caráter conversacional, apresenta-se como um grande exemplo do quanto implicado há por trás do que é expresso convencionalmente, ou seja, o quanto não-dito - mas ainda assim intencionado a ser transmitido - há por trás do dito.

\section{REFERÊNCIAS}

ARMENGAUD, F. A Pragmática. Tradução: Marcos Marcionilo. São Paulo: Parábola Editorial, 2006.

AUSTIN, J.L. Quando dizer é fazer: Palavras e ação. Porto Alegre: Artes Médicas, 1962.

BROWN, P. \& LEVINSON, S. Politeness. Cambridge: Cambridge University Press, 1987.

CHARAUDEAU, P. Linguagem e discurso: modos de organização. São Paulo: Contexto, 2009.

DAVIES, JIM. Garfield. 2009. Disponível em: < http://tirinhasdogarfield.blogspot.com. br> Acesso em: 03 de jun. de 2013, às 15h14min.

GRICE, H.P. Meaning. Philosophical Review, 66: p. 377-388, 1957.

Logic and Conversation. In: P. Cole and J. Morgan (ed.), Pragmatics (Syntax and Semantics), vol. 9, Nova York: Academic Press, 1975.

KOCH, I. V. A inter-ação pela linguagem. 10 ed. São Paulo: Contexto, 2006.

KOCH, I. V. \& ELIAS, V. M. Ler e compreender: os sentidos do texto. 2 ed., $1^{\text {a }}$ reimpressão. São Paulo: Contexto, 2007.

LINS, Maria da Penha P. O humor nas tiras de quadrinhos: Uma análise de alinhamentos e enquadres em Mafalda. Vitória: Grafer. 2002.

MEMES. 2013. Disponível em: <http://tirinhas-meme.tumblr.com/>. Acesso em: 03 de jun. de 2013, às 15h16min.

QUINO. Toda Mafalda. São Paulo: Martins Fontes, 2003.

RASKIN, V. Semantic Mechanisms of Humor. Dordrecht: D. Reidel, 1985.

TRAVAGLIA, L. C. Uma introdução ao estudo do humor pela linguística. Delta, v.6, n.1,1990, São Paulo/SP: Pontifícia Universidade Católica. p.55-82, 1990. 
SEARLE, J. R. Speech Acts: An Essay in the Philosophy of Language. Cambridge: CUP, 1969.

YULE, G. Pragmatics. Oxford: Oxford University Press, 1996.

XATARA, C. M. A tradução para o português das expressões idiomáticas em francês. Tese de Doutorado. Araraquara, São Paulo. Faculdade de Ciências e Letras, Universidade Estadual Paulista, 1998.

Recebido em: 03/06/2013

Aceito em: 30/06/2013 